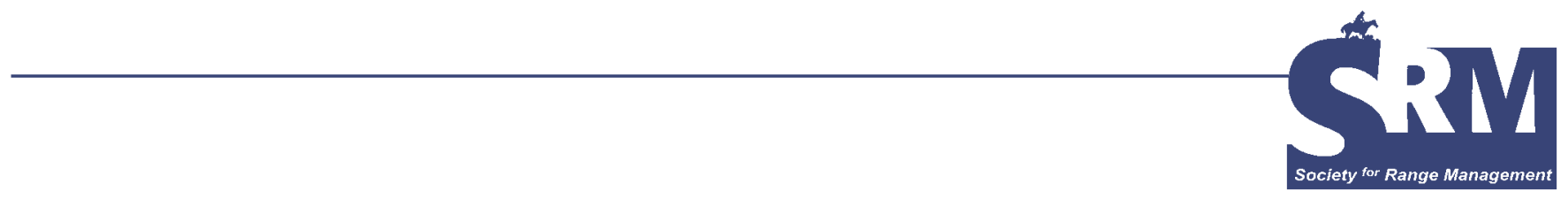

\title{
A Fish Out of Water
}

\section{By Jim Thorpe}

Editor's Note: This paper originally appeared in the SRM Nerw Mexico Section Spring 2005 newsletter.

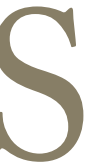

ometimes we gain perspective when plopped down in new surroundings. Last summer my wife and I had a chance to travel far off the ranch and explore the rocky coast of Maine. While loading up on clams and lobsters, investigating intriguing tidal zones, and wandering into a few too many lighthouses-turned-gift shoppes, I stumbled upon the realization that, while the coast and the range are indeed quite different worlds, they really are very much on the same planet. What led me to this observation (and Range Guys, if anything, are just naturally great observers) was The Working Waterfront, a local freebee publication that I picked up while Carol was scouring the LL Bean outlet mall.

We hear and talk a lot about rangelands these days as "working landscapes"; here, along side advertisements for bait, boats, boatyards, real estate, lobster festivals, and composting toilets, were discussions about the social and economic threats faced by "working waterfronts" and "traditional island communities." Instead of "sustainable grazing," the subject

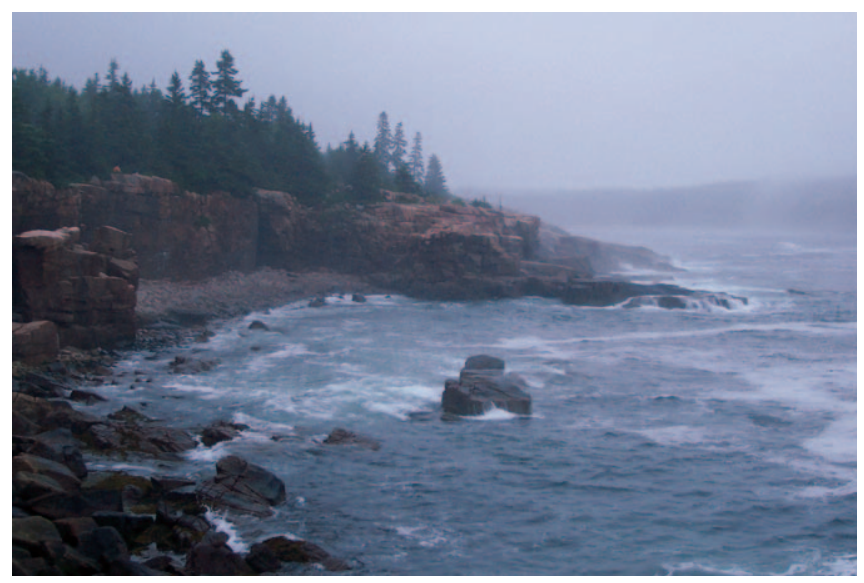

Shoreline interface: the rocky coast of Maine.

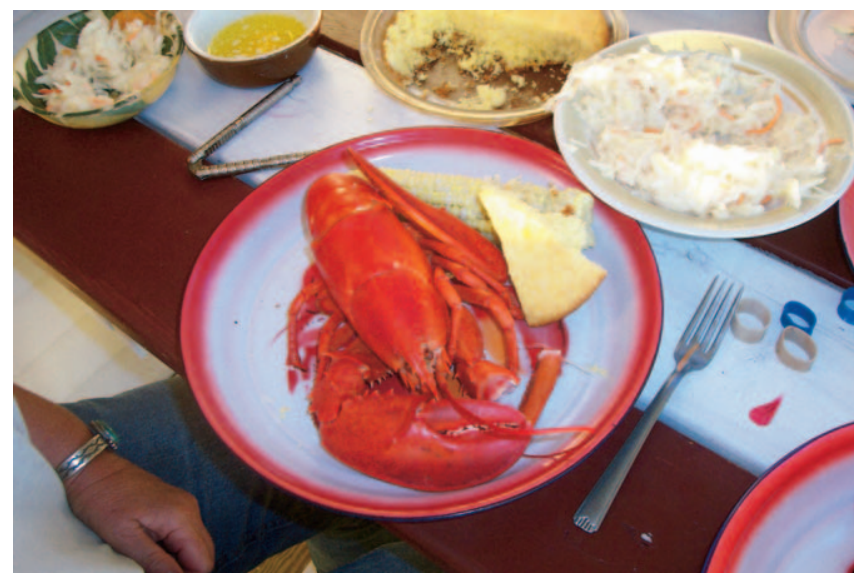

The Maine meal: a sustainable harvest?

was "sustainable fisheries." Instead of "ranchettes," it was "summer homes and megayachts." Instead of "ORVs" it was "PWCs" ("personal watercraft"-ie, jetskis). Instead of fights over AUM permits, it was "environmentalist lawsuits" over "DAS" ("Days at Sea") and "catch quotas"; these latter are said to often result in perverse effects, such as the throwing overboard of inadvertently caught (but now dead) quota-exceeding species (and FYI, endangered fish are never caught...).

There were similar-sounding calls for "sound science," and the combat of opposing advocates and agencies. Media savvy enviro-experts were pitted against old salts "out on the water" (these guys can read the surface of the water like a soil guy can read the surface of the land). Nothing less than the "very existence of island communities and their way of life" (not to mention, to give the activists their due, "the survival of the entire oceanic ecosystem") is said to be at stake, and "educating the public" seems to be a pressing need difficult for anyone to achieve.

The big question is "Where are all the fish?"- the millions of cod, herring, and other fishes that had once been pivotal in developing the original New England maritime economies. 


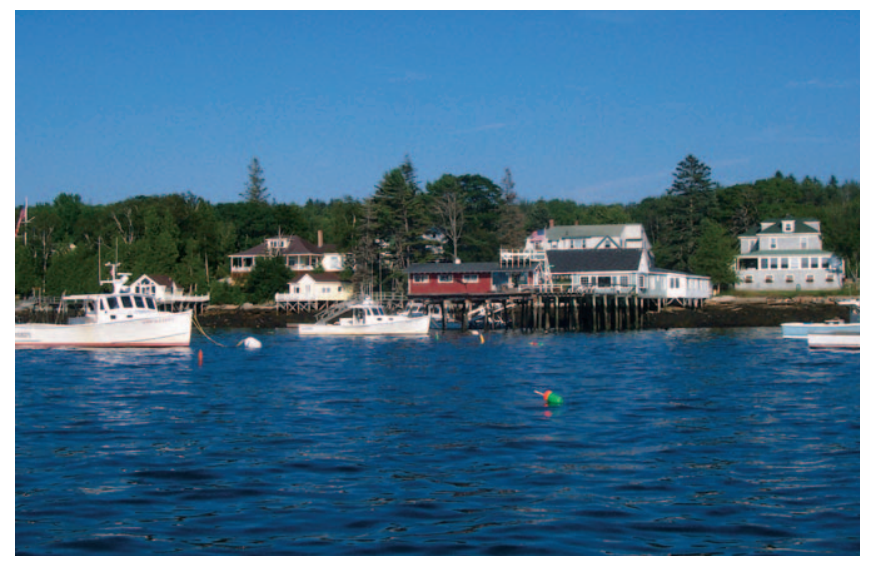

Lobster boats scenically moor offshore of swanky summer homes; lobstermen now live more modestly further inland.

These fish had once been an overabundant and seemingly inexhaustible resource (cf "swarms of buffalo" feeding on "grass up to their bellies"); now their numbers are so alarmingly depressed (up to $95 \%$, by some estimates) that the worry is, to translate into our contemporary range science dialect, that an irreversible "threshold" may have been crossed.

Restoration efforts and studies are underway. The "best available science" is striving to understand fish population dynamics and spawning habitats and is quantifying sustainable yields; an arsenal of high-tech devices has been deployed to probe the formerly murky depths. A massive tagging study hopes to catch, tag, and recatch 100,000 cod. A sort of derby is being run to enlist the help of commercial fisherman, who are (surprise?) frankly quite skeptical of the work of "government scientists who have come to help." Prizes such as coffee mugs and T-shirts are offered to those turning in the tagged fish (and GPS catch location), with the big incentive being that 1 in every 10,000 fish has a special tag worth $\$ 100$ ! A recent check on the Web site has noted that many more tagged fish are being recovered by Canadian fishermen than by Americans: go figure!

There are attempts to "retrain" displaced fishermen as data processors, security guards, and truck drivers, but it isn't so easy to teach old sea dogs new tricks. Those who wish to "stay on the water" might join the merchant marine or take up "oyster farming" or other forms of "aquaculture." Just about all salmon nowadays are "farmed," raised in shoreline pens that are akin to cattle feedlots, and while efficient, are not without their environmental challenges, such as diseases seeping out to imperil native "wild" fish or escapees turning into rampaging "invaders." And it turns out that the "trash" fish used to make salmon feed may be in danger of being overfished themselves (with the usual food chain disruption domino effect).

Lobstering seems to be the big success story, with lobster consumption (Dr Atkins is good for lobsters too, or so they say!) and catches at an all-time high, 3 times the levels of a decade ago (naturally this begs the sustainability question). While there are more traps in the water (tangling up more propellers of summer residents' pleasure craft) there are not really that many more fishermen; the established ones zealously guard their turf-much like in old-time range conflicts, newcomer lobster fishermen often find their traps robbed or cut adrift. (A cultural observation: instead of team-roping, lobstermen like to race special souped-up lobster boats in their spare time.)

Of course, it's not just only the fish who have problems, it's birds too. Apparently the Indians and early settlers used to raid the little island rookeries for their eggs. Many species, like Rosette Terns and Atlantic Puffins, were nearly extirpriated for their feathers (for fashionable ladies' hats). Now there are reintroduction efforts, especially as bird-watching tourists will pay good money to see them. (They are also something to look at on the "whale-watching cruises" when the whales don't show up!) Trouble is that the seagulls prey on their eggs and chicks; motivated summer interns are recruited to camp out on these islands and chase away the gulls, even destroying their nests when necessary (gull-lovers, however, are threatening to sue).

I was dwelling on the lead editorial ("Will Maine's island communities survive in the long run?") when it was time to go find some lunch (instead of a chile dog it was a "lobster roll"). I ruminated over the editorial's short answer while enjoying the fresh lobster meat stuffed into a hot-dog bun. Even with all the aforementioned challenges, Maine, with its often brutal climate, is not for "the faint hearted or the faithless" (nor is, for that matter, Clayton, New Mexico, in January or the "Jornada del Muerto" in July). The islands weren't going anywhere, so neither were their people. The parallel challenges faced by coastal and range communities, the pressing needs for applied sciences to address these, and the near-fatalistic dedication of their peoples to their working environments and livelihoods were thrown a bit into stark relief. It was cold comfort on a green summer day far from our home on the drought-tinted range.

Author is a rancher near Newkirk, NM, and a director of the New MexicoSection,jt@plateautel.net.

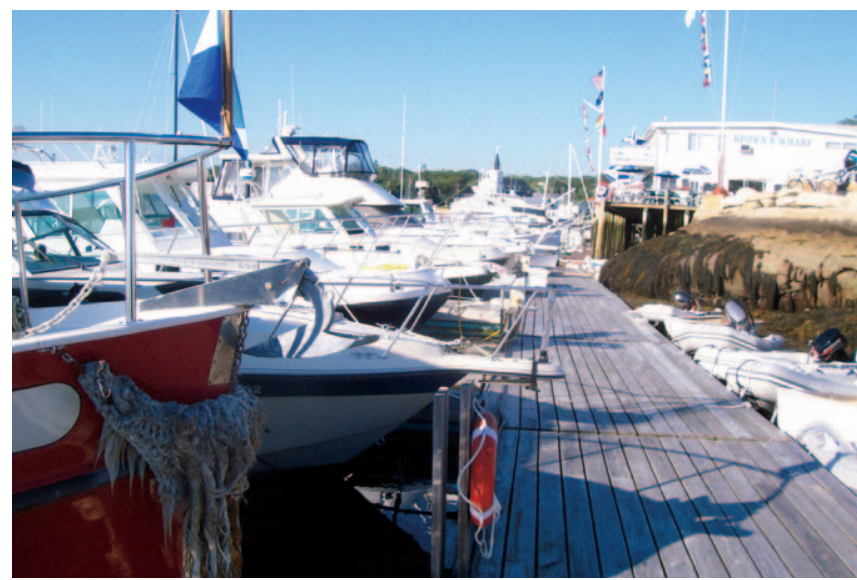

Bumper-to-bumper pleasure craft line a recreational waterfront. 